\title{
Investigation of Dyed Film Based on Quinaldine Red Dyed Poly(Vinyl Alcohol) and Poly(Vinyl Butyral) for High Dose Dosimetry Applications
}

\author{
Wafaa B. Beshir, Sayeda Eid \\ National Center for Radiation Research and Technology, Cairo, Egypt \\ Email: dr.wafaa@live.com
}

Received May 14, 2012; revised June 15, 2012; accepted June 26, 2012

\begin{abstract}
Dyed polymer films, prepared by a simple technique of casting aqueous solutions of poly(vinyl alcohol) PVA or poly(vinyl butyral) PVB containing quinaldine red (QR) on a horizontal glass plate, are useful as routine high-dose dosimeters. These flexible plastic film dosimeters are bleached when exposed to gamma rays. The response of these dosimeters depends on the concentration of QR and the polymer material. The radiation chemical yield (G-value) of both PVA and PVB dyed films was calculated and was found to increase with increasing dye concentration. The effect of relative humidity during irradiation as well as pre- and post-irradiation storage, on the response of the films is examined. These films are not affected by humidity change in the intermediate range of $10 \%-50 \%$.
\end{abstract}

Keywords: Quinaldine Red; Dosmetry; High Dose

\section{Introduction}

Many dyed poly films had been developed and investigated for possibility of their being used to measure absorbed doses in nuclear reactors and doses of X-rays, gamma rays and electron beam [1-6].

All these dyed PVA systems are bleached by irradiation the extent being to which the colour change is used for determining the absorbed dose. Radiation bleachable organic dyes were widely investigated [7]. For dose monitoring in radiation processing, the polymeric dyed flexible films are considered to be the most commonly used as dosimeters, indicators [8] based on the idea of mixing poly(vinyl alcohol) with two dyes having different sensitivities to radiation, a new label dosimetry system has been developed [9]. Dyed polymeric films containing organic dyes have been investigated to be a useful dosimeter in the high dose application [10].

In the current work, thin films of PVA or PVB coloured with different concentrations of quinaldine red were investigated to be used as dosimeters for radiation processing. The effect of humidity during irradiation as well as pre and post irradiation stability is examined.

\section{Experimental}

\subsection{Materials}

Quinaldine red indicator (product of E-Merck) molecular weight 430.352, PVA (average mo.wt 25.000 fully hy- drolyzed $99 \%-100 \%$ product of J.T baker chemical Co. USA) and poly(vinyl butyral) PVB, (piloform BM18) average molecular weight 36.000 , product of wacker Co., USA.

\subsection{Preparation of Stock Dye Solution}

The stock solution of quinaldine red indicator was prepared by dissolving $0.08 \mathrm{gm}$ in $50 \mathrm{ml}$ absolute ethanol.

\subsection{Preparation of Quinaldine Red Films}

Films were prepared by dissolving either $4.5 \mathrm{gm}$ of PVA (Average mo.wt 25.000 fully hydrolyzed 99\% - 100\% product of J. T baker chemical/CO. USA), in $90 \mathrm{ml}$ double distilled water or poly(vinyl butyral) in $90 \mathrm{ml} \mathrm{n}$-butanol. Complete dissolution was attained by stirring 3 hours at $60^{\circ} \mathrm{C}$ followed by continuous stirring for 24 hours at room temperature then lift to cool. For PVA and PVB films, polymer solution was divided into 3 parts each one of $30 \mathrm{ml}$ volume and $0.2,0.4,0.6 \mathrm{ml}$ of quinaldine red were added to each part. Each solution was poured on to $15 \times 15 \mathrm{~cm}$ horizontal glass plate and dried at room temperature for about $48 \mathrm{~h}$. After stripping the films were cut into $1 \times 1 \mathrm{~cm}$ pieces and were stored in the dark at $(\mathrm{RH})$ of $33 \%$, the film thickness was measured using digitrix-mark I thickness gauge to be $0.054 \pm$ $0.005 \mathrm{~mm}$. Six polymer films were obtained, three PVA films and three PVB films. Containing 0.021, 0.042 and 
$0.063 \mathrm{phr}(\mathrm{phr}=$ part per hundred parts by weight of resin).

\section{Instruments}

The absorption spectra of the unirradiated and irradiated films were measured in the wavelength range of 200 $800 \mathrm{~nm}$ using a UVIKON 860 spectrophotometer. The film thickness was measured using a Digitrix-Mark II thickness gauge (precision $\pm 1 \mu \mathrm{m}, 1 \sigma$ ). Irradiation was carried out with the ${ }^{60} \mathrm{Co}$ Gamma chamber $4000 \mathrm{~A}$ irradiation facility (manufactured at Bahabha Atomic Research Center, India). The absorbed dose rate in water was measured to be $3.75 \mathrm{kGy} / \mathrm{h}$ using reference alanine dosimeters. The temperature during gamma-ray irradiations was maintained at $37^{\circ} \mathrm{C} \pm 2^{\circ} \mathrm{C}$ and the electronic equilibrium conditions were during irradiation.

\section{Results and Discussion}

The absorption spectra of quinaldine red QR/PVA with $0.063 \mathrm{phr}$ dye were recorded before and after irradiation to different doses and are shown in Figure 1. Figure 2 shows the absorption spectra of QR/PVB with $0.042 \mathrm{phr}$ dye recorded before and after irradiation.

The absorption spectrum of the unirradiated quinaldine red film shows a main absorption band in the visible region characteristic to pink colour peaking at $547 \mathrm{~nm}$ for both PVA and PVB film Figure 1 curve (1), Figure 2 curve (1) the amplitude of this absorption band decreases gradually with the increase of gamma-ray-dose it can be noticed that the bleaching per unit dose of QR/PVA is much higher than that of QR/PVB.

\subsection{Response Curves}

For dosimetric purposes, optical density measured at 547 $\mathrm{nm}$ for both QR/PVA and QR/PVB films for different

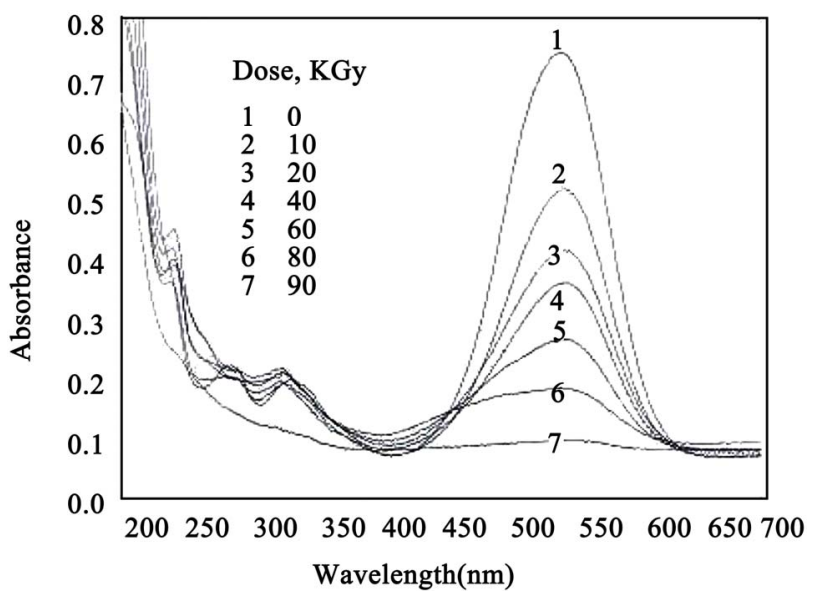

Figure 1. The absorption spectra of QR/PVA unirradiated and irradiated to different absorbed doses $(Q R)=0.063$ phr. dye concentrations $0.021,0.042$ and 0.063 phr Figures 3 and 4 shows the response curves in terms change in optical density per unit thickness, $\Delta \mathrm{A} \cdot \mathrm{mm}^{-1}$, versus the absorbed dose $\mathrm{D}$, where $\Delta \mathrm{A}=\mathrm{A}_{\mathrm{o}}-\mathrm{A}_{\mathrm{i}}$ and $\mathrm{A}_{\mathrm{o}}$ and $\mathrm{A}_{\mathrm{i}}$ are values of

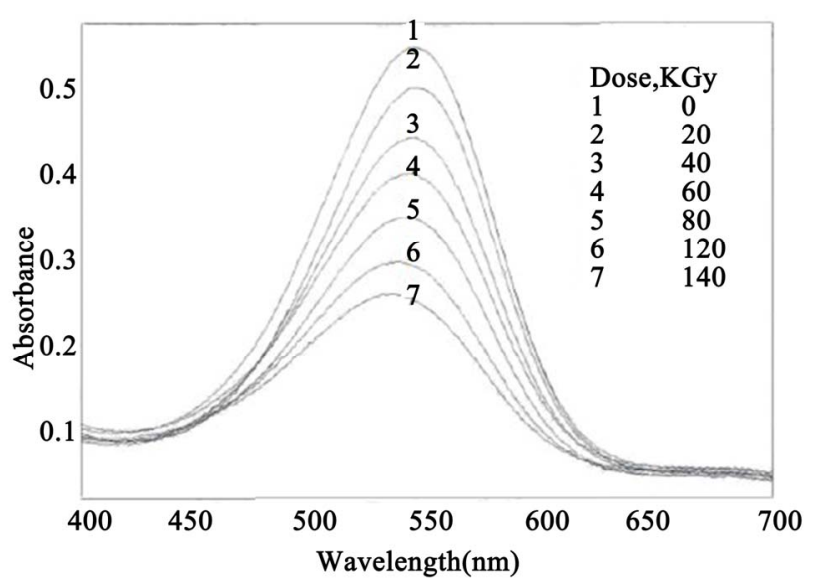

Figure 2. The absorption spectra of QR/PVB unirradiated and irradiated to different absorbed doses $(Q R)=0.042$ phr.

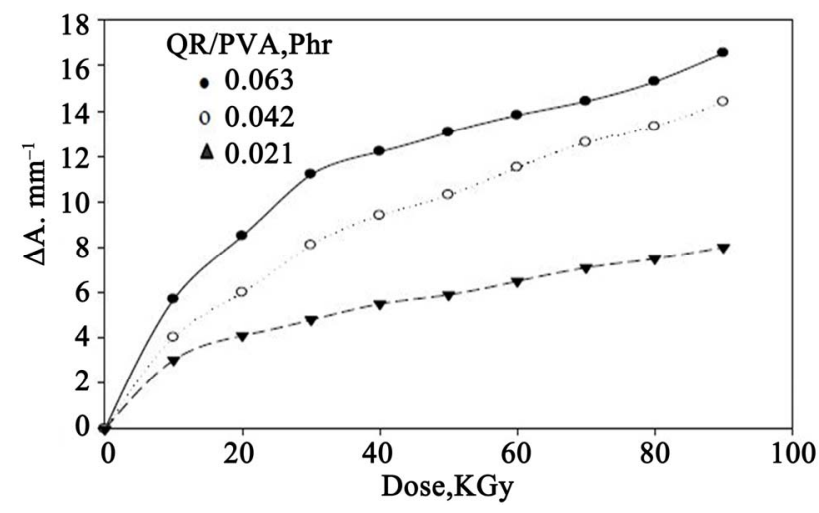

Figure 3. Change of $\Delta \mathrm{A} \cdot \mathrm{mm}^{-1}$, as a function of absorbed dose for different $(\mathrm{QR})$ concentrations in PVA films.

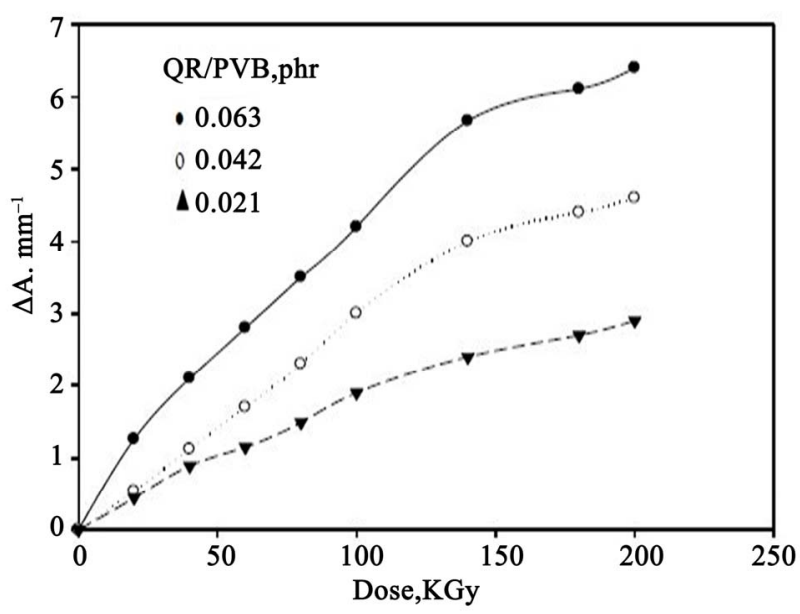

Figure 4. Change of $\Delta \mathrm{A} \cdot \mathrm{mm}^{-1}$, as a function of absorbed dose for different (QR) concentration in PVB films. 
optical densities for the unirradiated and irradiated film respectively. The curves show that the maximum dose range extends up to $90 \mathrm{kGy}$ for QR/PVA films and 200 $\mathrm{kGy}$ for $\mathrm{QR} / \mathrm{PVB}$ films, it can be seen that all curves have the same trend but differ in their slopes depending on dye concentration.

\subsection{Radiation-Chemical Yield}

The radiation chemical yield (G-value) is defined as the number of moles of dye degraded by the absorption of 1 $\mathrm{J}$ of energy (unit, mol/J). The G-value is calculated from the general relation [11].

$$
\mathrm{G}(-\mathrm{dye})=\Delta \mathrm{A} / \mathrm{D} \varepsilon \cdot \mathrm{b} \rho
$$

where $\Delta \mathrm{A}$ is the change in the absorbance at $\lambda_{\max } \mathrm{b}$ is the optical path length $(\mathrm{cm}), \varepsilon$ is the linear molar or extinction coefficient at $\lambda_{\max }\left(\mathrm{L} \cdot \mathrm{mol}^{-1} \cdot \mathrm{cm}^{-1}\right), \rho$ is the density of the dosimeter $\mathrm{gm} \cdot \mathrm{cm}^{-3}, \mathrm{D}$ is absorbed dose (Gy). Using the dye concentration in $\mathrm{mol} / \mathrm{L}$ and the average value of $\mathrm{A}_{\mathrm{o}} / \mathrm{b}$, the, molar extinction coefficient, $\varepsilon$ is calculated as $108384.44 \mathrm{~L} \cdot \mathrm{mol}^{-1} \cdot \mathrm{cm}^{-1}$ for QR/PVA and 104480.63 $\mathrm{L} \cdot \mathrm{mol}^{-1} \cdot \mathrm{cm}^{-1}$ for $\mathrm{QR} / \mathrm{PVB}$. Using the density of either PVA $\left(1.25 \mathrm{gm} \cdot \mathrm{cm}^{-3}\right)$ or PVB $\left(1.1 \mathrm{gm} \cdot \mathrm{cm}^{-3}\right)$ to calculated the G-value in terms of $\mu \mathrm{mol} / \mathrm{J}$. The calculated G-vale for both kinds of films and the concentration of the dye inside the film matrix were tabulated in Table 1.

From the table it could be noticed that for the same dye concentrations the G-value in PVA is higher than that in PVB films. This may be due to the number of radiolysis products of PVA compared with that in PVB, this results reflects the important role of the polymer matrix in the bleaching process.

\section{Humidity during Irradiation}

The effect of relative humidity $(\mathrm{RH})$ during irradiation on the response of these films was investigated by irradiating QR/PVA (30 kGy) and QR/PVB (60 kGy) films at the different relative humidifies $(0 \%, 12 \%, 23 \%, 54 \%$, $76 \%$ and $92 \% \mathrm{RH})$. The different relative humidity was maintained by using different standard salts [12]. The films were stored before irradiation for three days period under the same relative humidity conditions as when irradiated, so that equilibrium moisture content in dosimeter is established during irradiation.

Table 1. The calculated G-value for both QR/PVA and QR/ $P V B$ at different dye concentration.

\begin{tabular}{ccc}
\hline \multirow{2}{*}{ Dye conc. phr } & \multicolumn{2}{c}{ G-value } \\
\cline { 2 - 3 } & QR/PVA $\mu \mathrm{mol} \cdot \mathrm{J}^{-1}$ & $\mathrm{QR} / \mathrm{PVB} \mu \mathrm{mol} \cdot \mathrm{J}^{-1}$ \\
\hline 0.021 & 0.02096 & $0.189 \times 10^{-2}$ \\
0.042 & 0.02795 & $0.21018 \times 10^{-2}$ \\
0.063 & 0.04325 & $0.429 \times 10^{-2}$ \\
\hline
\end{tabular}

Figure 5 represents the relative variation in $\mathrm{A}_{\mathrm{i}} / \mathrm{A}_{0}$ at $547 \mathrm{~nm}$ for QR/PVA and QR/PVB as function of percentage relative humidity during irradiation, relative to that at $33 \%$ one it can be seen that for PVB films, the response of the films are almost flat in the range of relative from $0 \%-95 \%$, where the variation in response over the whole $\mathrm{RH}$ range, never exceeds $5 \%$. While in QR/ PVA films, there is a gradual decrease in Response with the increase of RH. This film can be used in the $\mathrm{RH}$ range from $10 \%-50 \% \mathrm{RH}$.

\section{Stability}

\subsection{Pre-Irradiation Stability}

The colour stability of QR/PVA and QR/PVB films were tested before irradiation by storing the films at $35 \% \mathrm{RH}$ at room temperature under laboratory fluorescent light. Figure 6 represents the change in $A_{i} / A_{o}$ of the tested films, were measured at $547 \mathrm{~nm}$ for both PVA and BVB films at different intervals time during the storage period of 30 days. It can be seen that, both films exhibit excellent stability before irradiation, where he variation in absorbance during the 30 days storage period is less than $\pm 2 \%$.

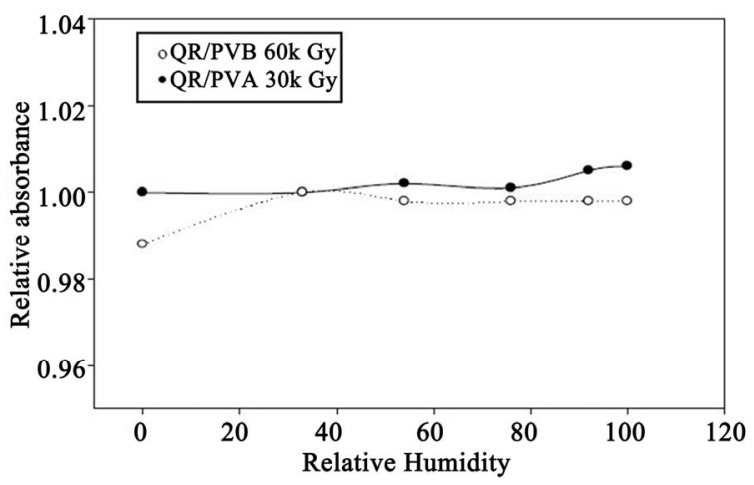

Figure 5. Variation of relative response $A i / A_{0}$ of both $Q R / P V A$ and $\mathrm{QR} / \mathrm{PVB}$ as a function of relative humidity during irradiation, QR/PVA and QR/PVB irradiated to 30 and $60 \mathrm{kGy}$.

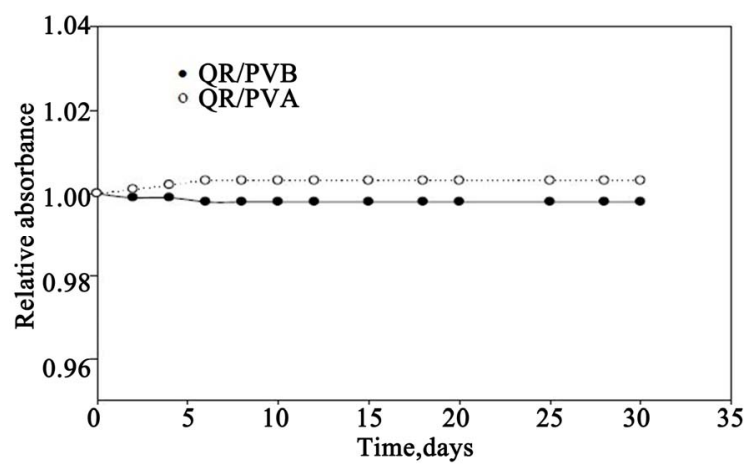

Figure 6. Pre-irradiation stability of both QR/PVA and QR/ $P V B$ films in terms of relative change in absorbance as a function of storage time. 


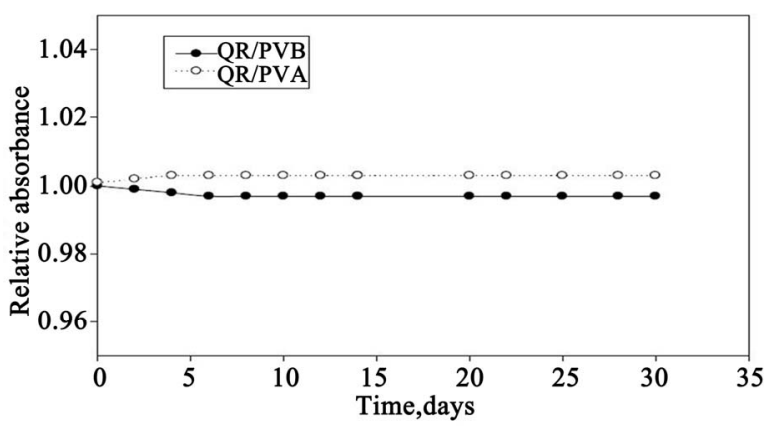

Figure 7. Post-irradiation stability of both QR/PVA and $\mathrm{QR} / \mathrm{PVB}$ films in terms of relative change in absorbance as a function of storage time, where $Q R / P V A$ and $Q R / P V B$ films irradiated to and $40 \mathrm{kGy}$.

\subsection{Post-Irradiation Stability}

QR/PVA and QR/PVB films containing $0.063 \mathrm{phr}$ of dye irradiated to a dose of $40 \mathrm{kGy}$, then stored at $35 \% \mathrm{RH}$ at room temperature $25^{\circ} \mathrm{C} \pm 30^{\circ} \mathrm{C}$ in the laboratory fluorescent light the absorbance these films were measured at $547 \mathrm{~nm}$ for both PVA and PVB films at different intervals of time during the storage period of 30 days. The change in absorbance as a function of storage time relative to that zero time immediately after irradiation are showing in Figure 7. From this figure, it can be seen that, QR/PVB films shows a good stability, while QR/PVA films show a gradual decrease in absorbance with around $3 \%$ during the first 10 days then tends to be stable to the end of the storage period.

\section{Conclusions}

Films of PVA or PVB dyed with Quinaldine Red are useful dosimeters in the dose ranges $10-90$ and $30-200$ kGy respectively.

The films considered being highly stable for long times before and after irradiation and have negligible humidity effects in the range of $0 \%-50 \% \mathrm{RH}$ as well as they are easy to prepare in a laboratory and do not require toxic solvents in the preparation, the above properties suggest there to be useful for routine monitoring and dose mapping in radiation processing.

\section{REFERENCES}

[1] F. Abdel-Rehim, A. Miller and W. L. McLaughlin, "Response of Radiation Monitoring Labels to Gamma Rays and Electrons," Radiation Physics and Chemistry, Vol. 25, No. 4-6, 1985, pp. 767-775.

\section{doi:10.1016/0146-5724(85)90157-8}

[2] F. Abdel-Rehim, S. Ebraheem, W.-Z., Ba and W. L. McLaughlin, "A Thin Dyed Plastic Dosimeter for Large Radiation Doses," Applied Radiation and Isotopes, Vol. 43, No. 12, 1992, pp. 1503-1510. doi:10.1016/0883-2889(92)90179-I

[3] F. Abdel-Rehim, S. Ebraheem and N. Souka, "A New Label Dosimetry System," Radiation Physics and Chemistry, Vol. 39, No. 2, 1992, pp. 191-195.

[4] A. A. Abdel-Fattah, M. El-Kelany and F. Abdel-Rehim, "Development of a Radiation-Sensitive Indicator," $R a$ diation Physics and Chemistry, Vol. 48, No. 4, 1996, pp. 497-503. doi:10.1016/0969-806X(96)00014-X

[5] A. A. Abdel-Fattah and A. Miller, "Temperature, Humidity and Time Combined Effects on Radiochromic Film Dosimeter," Radiation Physics and Chemistry, Vol. 47, No. 4, 1996, pp. 611-621. doi:10.1016/0969-806X(95)00037-X

[6] M. Kattan, Y. Daher and H. Alkassiri, "A High-Dose Dosimeter-Based Polyvinyl Chloride Dyed with Malachite Green," Radiation Physics and Chemistry, Vol. 76, No. 7, 2007, pp. 1195-1199. doi:10.1016/j.radphyschem.2006.12.004

[7] S. Ebrahim, W. B. Beshir and S. Eid, "Investigation of Dyed Film Based on 2,6-Dichloro Phenol-Indophenol Dyed Poly(Vinyl Alcohol) and Poly(Vinyl Butyral) for Possible Use in High Dose Processing Dosimetry," Arab Journal of Nuclear Sciences and Applications, Vol. 38, No. 1, 2005, pp. 15-22.

[8] F. Abdel-Rehim and A. A. Abdel-Fattah, "A Thin Film Radiation Monitoring Label and Dosimetry System," Applied Radiation and Isotopes, Vol. 44, No. 7, 1993, pp. 1047-1053. doi:10.1016/0969-8043(93)90010-8

[9] A. A. Abdel-Fattah, S. Ebraheem, M. El-Kelany and F. Abdel-Rehim, "High Dose Film Dosimetry Based on Bromophenol Blue or Xylenol Orange Dyed Poly Vinyl Alcohol," Applied Radiation and Isotopes, Vol. 47, No. 3, 1996, pp. 345-350. doi:10.1016/0969-8043(95)00266-9

[10] S. Ebraheem, M. A. El-Ahdal, S. Eid and S. M. Gafar, "Investigation of Dyed Poly(Vinyl Alcohol) Films for HighDose Dosimetry Applications," Egyptian Journal of Radiation Science and Applications, Vol. 23, No. 2, 2010, pp. 379-391.

[11] W. L. Mclaughlin, A. W. Boyd, K. H. Chadwick, J. C. McDonald and A. Miller, "Dosimetry for Radiation Processing," Taylor of Francis, London, 1989.

[12] H. Levine, W. L. Mclaughlin and A. Miller, "Temperature and Humidity Effects on the Gamma-Ray Response and Stability of Plastic and Dyed Plastic Dosimeters," Radiation Physics and Chemistry, Vol. 14, No. 3, 1979, pp. 551-574. doi:10.1016/0146-5724(79)90091-8 